Article

\title{
Recent Advances in Industrial Sulfur Tolerant Water Gas Shift Catalysts for Syngas Hydrogen Enrichment: Application of Lean (Low) Steam/Gas Ratio
}

\author{
Bonan Liu ${ }^{1,2, *}$, Liang Zhao ${ }^{1}$, Zhijie Wu ${ }^{1}{ }^{1}$, Jin Zhang ${ }^{2}$, Qiuyun Zong ${ }^{2}$, Hamid Almegren ${ }^{3}$, \\ Feng Wei ${ }^{4}$, Xiaohan Zhang ${ }^{1}$, Zhen Zhao ${ }^{1}$, Jinsen Gao ${ }^{1}$ and Tiancun Xiao ${ }^{5, *}$ \\ 1 State Key Laboratory of Heavy Oil Processing, China University of Petroleum (Beijing), 18 Fuxue Road, \\ Changping District, Beijing 102249, China; liangzhao@cup.edu.cn (L.Z.); zhijiewu@cup.edu.cn (Z.W.); \\ zxh19950925@126.com (X.Z.); zhenzhao@cup.edu.cn (Z.Z.); jsgao@cup.edu.cn (J.G.) \\ 2 Industrial Engineering Laboratory of Sulfur Tolerant Water Gas Shift Catalyst Subjected to China Petroleum \\ and Chemical Industry Federation (CPCIF), Qingdao Lianxin Catalyst Company, Yunxi Road, Jiaozhou \\ 266300, Shandong Province, China; zhangjin19870227@163.com (J.Z.); zqy1959@163.com (Q.Z.) \\ 3 Materials Research Institute, KACST, PO Box 6086, Riyadh 11442, Saudi Arabia; almegren@kacst.edu.sa \\ 4 State Key Laboratory of Advanced Materials for Smart Sensing, General Research Institute for Nonferrous \\ Metals, 11 Xingkedong Street, Huairou District, Beijing 101402, China; weifeng@grinm.com \\ 5 KACST-Oxford Petrochemical Research Centre, Inorganic Chemistry Laboratory, University of Oxford, \\ South Parks Road, Oxford OX1 3QR, UK \\ * Correspondence: liubonan@cup.edu.cn (B.L.); xiao.tiancun@chem.ox.ac.uk (T.X.)
}

Received: 16 July 2019; Accepted: 10 September 2019; Published: 14 September 2019

\begin{abstract}
A novel sulfur tolerant water gas shift (SWGS) catalyst has been developed for the applications under lean (low) steam/gas ratio conditions, which has been extensively used for $\mathrm{H}_{2} / \mathrm{CO}$ adjustment of syngas and $\mathrm{H}_{2}$ enrichment in the world since 2000s with safer operation and lower steam consumption. Technology design and catalyst performances under different lean steam/gas conditions were comprehensively reported. Industrial data were collected from several large scale running plants with a variety of served catalysts characterized and precisely re-examined in the laboratory. It is shown that the developed Mo-Co/alkali/ $/ \mathrm{Al}_{2} \mathrm{O}_{3}$ SWGS catalyst can operate very steadily even with the steam/gas ratio as low as $0.2-0.3$, and the main deactivation factors are accidental caking, sintering, as well as poisoning impurities, such as As or Cl. The adoption of lean steam/gas SWGS catalyst can significantly improve the plant efficiency \& safety and remarkably reduce the actual steam consumption for $\mathrm{H}_{2}$ production, which can decrease $\mathrm{CO}_{2}$ emission correspondingly. The work helps to evaluate how specially designed SWGS catalysts performed under applied lean steam/gas conditions, providing important references for researchers and industry.
\end{abstract}

Keywords: Sulfur tolerant water gas shift catalyst; steam/gas ratio; Mo-Co/alkali/ $\mathrm{Al}_{2} \mathrm{O}_{3}$ catalyst; catalyst deactivation; syngas; $\mathrm{H}_{2}$ production

\section{Introduction}

Water gas shift (WGS) reaction is a key step of hydrogen $\left(\mathrm{H}_{2}\right)$ enrichment in many important industrial sectors where syngas $\left(\mathrm{CO}+\mathrm{H}_{2}\right)$ is routinely generated from biomass, residue oil, coal and natural gas [1,2]. Such a process plays a unique role in the adjustment of syngas $\mathrm{CO} / \mathrm{H}_{2}$ ratio, syngas quality upgrade by $\mathrm{H}_{2}$ enrichment, and more importantly bringing in a diversity for downstream productions [1-4]. The reaction stands on a mars-van Krevelen mechanism according to which one oxygen atom is transferred from $\mathrm{H}_{2} \mathrm{O}$ to $\mathrm{CO}$ leading to the liberation of $\mathrm{H}_{2}$ and the formation of $\mathrm{CO}_{2}$ [5]. 
Explorations on WGS never stopped with many new catalysts continuously developed in the laboratory, such as the recent advances in supported gold catalyst for low-temperature WGS [6-10]. However, the huge cost of noble metal inevitably limits the scaling up of such novel catalysts $[6,8]$. In fact, as the purification of syngas, e.g., sulfur removal, is always expensive, $\mathrm{Mo}-\mathrm{Co} / \mathrm{Al}_{2} \mathrm{O}_{3}$-based catalysts with sulfur-tolerance are still being used as the major industrial WGS catalyst, especially for sulfur-containing syngas, referred as sulfur tolerant (sour) water gas shift (SWGS) catalyst [11,12].

Reaction conditions are undoubtedly crucial for the industrial SWGS process leading to many important improvements in technology to decrease the actual production costs, e.g., water usage, and corresponding changes in the designed catalysts. In this work, the application of newly developed lean (low) steam/gas (ratio) technology for SWGS as well as the performance of designed catalysts are comprehensively reported, as one of the most important recent advances in the syngas industry [13,14].

\section{Lean Steam/gas (Ratio) Sulfur Tolerant Water Gas Shift}

The WGS system mainly contains five general compounds, i.e., $\mathrm{CO}, \mathrm{CO}_{2}, \mathrm{H}_{2}, \mathrm{H}_{2} \mathrm{O}$ and $\mathrm{CH}_{4}$, which are supposed to maintain a balance under given reaction conditions. Two reactions proceed in a parallel way to decide the final product composition.

(1) Water gas shift as the main reaction

$$
\mathrm{CO}(\mathrm{g})+\mathrm{H}_{2} \mathrm{O}(\mathrm{g}) \leftrightarrow \mathrm{CO}_{2}(\mathrm{~g})+\mathrm{H}_{2}(\mathrm{~g})(\Delta \mathrm{H}=-41.1 \mathrm{~kJ} / \mathrm{mol})
$$

(2) Methanation of $\mathrm{CO}$ as the core side reaction

$$
\mathrm{CO}(\mathrm{g})+3 \mathrm{H}_{2}(\mathrm{~g}) \leftrightarrow \mathrm{CH}_{4}(\mathrm{~g})+\mathrm{H}_{2} \mathrm{O}(\mathrm{g})(\Delta \mathrm{H}=-206.3 \mathrm{~kJ} / \mathrm{mol})
$$

WGS reaction is mildly exothermic while methanation is commonly known as strongly exothermic. Intensive methanation consumes $\mathrm{H}_{2}$; in addition, it often leads to an unpredictable, suddenly raised catalyst bed temperature which causes the damage of catalyst structure. In the real industrial process of syngas refining, to obtain a satisfied $\mathrm{CO} / \mathrm{H}_{2}$ ratio, methanation should be strictly avoided in the WGS section $[1,2,15,16]$. One useful method is to overfeed the content of water (steam) in the reactant stream which helps to selectively promote the WGS main reaction while effectively suppressing methanation with the reaction equilibrium; thus, a high steam/gas (dry syngas without water) ratio should be applied. For SWGS in the coal/natural gas industry, the steam/gas ratio employed by a pre-reactor (R1) is routinely 1.6 or higher $[12,13,17]$.

Water (steam) consumption became another challenge when a high steam/gas ratio was applied. On the other hand, the overfed steam used to avoid methanation may also overpromote WGS reaction with an equilibrium temperature interval up to several hundred degrees. In such case, the control of WGS reaction depth became undesirably difficult and therefore the catalyst bed temperature rapidly went up. The only way to avoid superfluous heat was reducing the actual catalyst loading for each reactor $[13,17]$.

With modified anti-methanation and water-capture features, SWGS catalysts can be used under lean (lower) steam/gas ratio ( 0.5 or lower) conditions. It was until 2003 that the world's first industrialization of SWGS with a lean steam/gas ratio was successfully applied in China $[13,14]$. Some plants have been smoothly running for more than 10 years with an average catalyst lifetime of 3-4 years. The adoption of such catalysts requires changes in technological process as explained in Figure 1 [17]. 

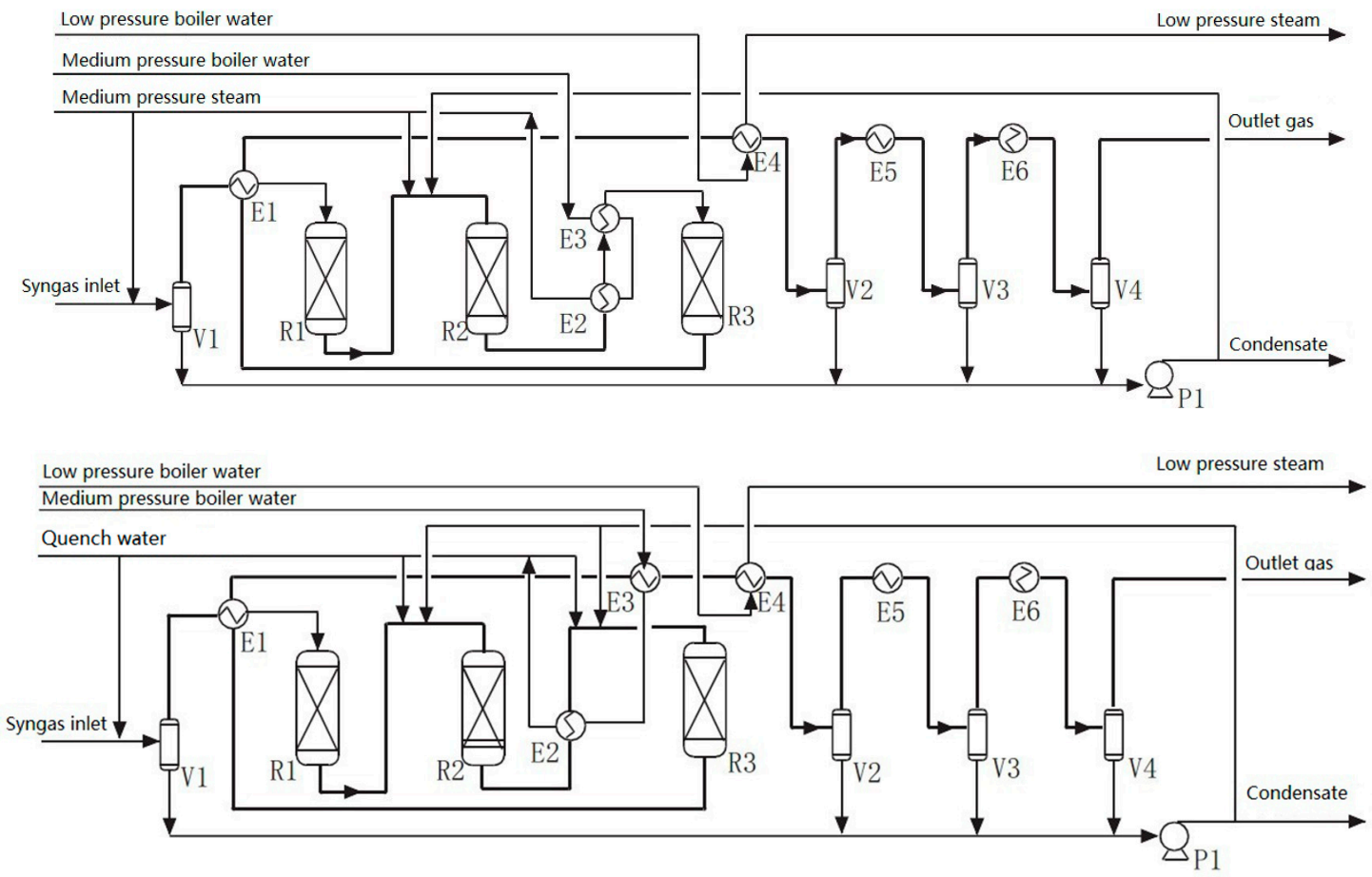

Figure 1. High (1.6 or higher) steam/gas ratio WGS (top) vs. Low steam/gas ratio WGS (bottom). E1 preheater; E2 medium pressure waste heat boiler; E3 preheater of medium pressure boiler water; E4 low pressure waste heat boiler; E5 desalted water preheater; E6 recycling water cooler; P1 condensation pump; V1-V4 separators; R1 pre WGS reactor; R2 the 1st WGS reactor; R3 the 2nd WGS reactor; figures adjusted from other researchers' work [17].

When applied in the SWGS process (Figure 1), high steam/gas ratio technology (HSGRT) does not require water complementation before a 2nd WGS reactor (R3); however, medium pressure steam used for a reaction will be added into the pre WGS reactor (R1) and 1st WGS reactor (R2), respectively. Instead of steam, lean steam/gas ratio technology (LSGRT) possesses three quench water injections in front of R1, R2 and R3, respectively. In each reactor quench, water vaporized into steam with heat is released from the reaction (there is no need to use out heat), and such improvement has been proven to effectively reduce the actual plant steam consumption and energy cost with the WGS (SWGS) reaction rate being better controlled by the injected quench water amount [17].

Table 1 presents the real industrial data obtained from a 0.5 million ton/year methanol synthesis project (Zhong Yuan Da Hua Coal Chemistry Group, Henan Province, China) employed Shell gasification for syngas production.

As the original steam/gas ratio ( $~ 0.3$ or higher) of crude syngas had already satisfied the requirement for LSGRT, there was no water complementary, either in terms of steam or quench water. The steam cost (35-60 ton/hour) fell to nearly zero by technological upgrade from HSGRT to LSGRT. On the other hand, the condensed water generation correspondingly reduced from 30-55 ton/hour to $0-5$ ton/hour. Noteworthily, with no extra steam added, the steam/gas ratio of each reactor could be maintained at a uniform (0.23-0.26) by LSGRT as a significant advance. At the same time, with the steam (water) amount inside SWGS system steadily controlled, methanation was effectively suppressed and the undesired catalyst bed temperature 'flying away' (the suddenly occurred temperature increasement due to methanation) was also prohibited.

Industrial data from the SWGS plants of a 4 million ton/year Coal-to-Liquid project (Shenhua Ningxia Coal Industry Group, Ningxia Province, China) are more encouraging. The project employed GSP gasification (pressurized pulverized coal gasification) to give an initial steam/gas ratio of $\sim 1.0$ for the raw syngas, which already exceeded the steam usage requirement for LSGRT. After upgrading to LSGRT, there was no need to add extra steam into the SWGS process; for a single SWGS reactor 
$\mathrm{R} 2$, the overall saved cost on steam was approximately $1.04 \times 10^{9} \mathrm{RMB}$, equivalent to $1.52 \times 10^{8} \mathrm{USD}$ every year.

Table 1. Industrial data from SWGS plants of a 0.5 million ton/year methanol synthesis project (Zhong Yuan Da Hua Coal Chemistry Group, Henan Province, China);. Catalytic performances were compared between the high (1.6 or higher) steam/gas ratio technology and low ( 0.3 or lower) steam/gas ratio technology.

\begin{tabular}{cccccccc}
\hline \multirow{2}{*}{ SWGS } & Rector & \multicolumn{2}{c}{ Steam/Gas } & \multicolumn{2}{c}{ Temperature, ${ }^{\circ} \mathbf{C}$} & Steam Cost \\
\cline { 2 - 6 } & & Inlet & Outlet & Inlet & Hot Spot & $\begin{array}{c}\text { Condensed Water } \\
\mathbf{t} / \mathbf{h}\end{array}$ \\
\hline \multirow{3}{*}{ HSGRT } & R1 & 1.82 & 0.79 & 286 & 502 & & \\
& R2 & 0.79 & 0.49 & 260 & 373 & $35-60$ & $30-55$ \\
& R3 & 0.49 & 0.35 & 240 & 336 & & \\
\multirow{2}{*}{ LSGRT } & R1 & 0.26 & 0.03 & 210 & 417 & & $0-5$ \\
& R2 & 0.23 & 0.04 & 210 & 371 & 0 & \\
\hline
\end{tabular}

Data were collected by the catalyst inventors from Qingdao Lianxin Catalyst Company who are the co-authors of the current work.

\section{Catalysts Used for Lean Steam/Gas (Ratio) Sulfur Tolerant Water Gas Shift}

Syngas from the gasification and partial oxidation of heavy oil, tar sands, coal, coke or biomass contain much larger concentrations of $\mathrm{CO}$ (up to $50 \mathrm{~mol} \%$ ) and sulfur levels of $5-50 \mathrm{ppm}$, as a result of which both sulfur tolerance and effective $\mathrm{CO}$ activation are crucial for conventional SWGS catalysts. A standard commercial SWGS catalyst composition is based on Co (Ni)-Mo/alumina, here the core catalytic function relies on the effective $\mathrm{CO}$ activation of sulfurized Mo sites while other metal species, e.g., Cobalt, are co-catalytic sites or promoters helping in the effective electron transportations $[10,11,18-20]$. The accelerated $\mathrm{CO}$ conversion requires more water molecules to finish the reaction. It is, hence, necessary to either operate at higher steam/gas (or $\mathrm{H}_{2} \mathrm{O} / \mathrm{CO}$ ) ratios or use extra volume of catalysts to support the desired CO conversion [10,11,18-21].

One question is to what extent the water molecules used by high steam/gas conditions are utilized to successfully convert $\mathrm{CO}$ into $\mathrm{CO}_{2}$, or whether the enriched water concentration would affect the WGS reaction in practice. Herein, the interaction between catalytic sites and water molecules becomes a key point. The secret behind LSGRT for SWGS is its enhanced water (steam) capture by employed catalyst [13]. It is well known that the WGS catalyst promotes both water gas shift and methanation reactions. In a closed system reaction equilibrium works to draw the final product composition; however, in a constant flow system, e.g., the WGS reactor, the utilization of catalytic sites by different reactants dominates the product output $[12,18,21]$. By applying a specially designed SWGS catalyst with better water-capture ability, $\mathrm{H}_{2} \mathrm{O}$ molecules were selectively enriched on/near the catalytic sites to meet the requirement of accelerated $\mathrm{CO}$ conversions, while the $\mathrm{H}_{2}$ adsorption on catalytic sites was effectively weakened. The first effect greatly promotes the WGS reaction and enables step-wised control of WGS reaction depth with even very limited water amount; the second effect better suppresses the methane formation.

Inclusion of alkali oxides into the Mo-Co/alumina composition brings the above enhanced water capture ability to LSGRT SWGS catalysts. The increase of $\mathrm{K}_{2} \mathrm{O}$ content in $\mathrm{MgAl}_{2} \mathrm{O}_{4}$ spinel modified alumina supported $\mathrm{CoMoOx}$ catalyst (general form of conventional $\mathrm{Mo}-\mathrm{Co} / \mathrm{Al}_{2} \mathrm{O}_{3}$ catalyst for SWGS) led to higher $\mathrm{CO}$ conversions under the lean steam/gas conditions while effectively suppressing the formation of $\mathrm{CH}_{4}[13,14]$. It was thought that $\mathrm{K}_{2} \mathrm{CO}_{3}$ helped in the capture of water molecules while the alkalinity of $\mathrm{K}_{2} \mathrm{CO}_{3}$ also effectively depressed methane formation over the $\mathrm{MoS}_{2}$ active sites.

A general composition of industrial Mo-Co/alkali/ $/ \mathrm{Al}_{2} \mathrm{O}_{3}$ catalyst for LSGRT is given as below (based on the evaluation of $\mathrm{X}$-ray fluorescence spectroscopy, atom weight):

Na 1-3\%, Mg 0-1\%, Al 65-80\%, K 0-15\%, Ca 0-5\%, Mo 5-10\%, and Co 0-5\%. 
In this paper, we have selected representative samples of a laboratory-developed LSGRT SWGS catalyst (marked as CAT) that has been and is being employed in the SWGS plant of many large scale coal/natural-gas chemistry projects in the Chinese industry. Samples of different running time, and various deactivations were characterized and re-evaluated in laboratory.

\section{Catalyst Performances and Characterizations}

Residual catalytic properties of served/deactivated samples were measured by rationally designed laboratory experiments using as-prepared (sulfurized in factory) CAT for reference. The experimental system (Figure 2) employed two fixed-bed reactors connected in series in order to better simulate the real SWGS process (R1 used for pre-sulfurization was removed to show the authentic residual catalytic property of served/deactivated industrial samples, all samples were vacuumed immediately at the time of unloading; the reactor 1 and reactor 2 in Figure 2 simulated the R2 and R3 SWGS reactors in Figure 1, respectively). Each time, $0.3 \mathrm{ml}$ catalysts ground and sieved into $40-60$ mesh were loaded in the isothermal zone of each reactor (quartz wool and quartz sand were used for protection and supporting). $\mathrm{N}_{2}(100 \mathrm{ml} / \mathrm{min})$ was used as a carrier gas to bring steam into the reactors. Water was vaporized in the calibrated two-stage evaporators, and the steam/gas ratio was precisely set at 0.7 , a bit higher than the real LSGRT to guarantee the $\mathrm{CO}$ conversion over served/deactivated samples. The inlet dry gas (50 ml/min) contained $\mathrm{CO}$ of $45 \mathrm{vol} \%, \mathrm{CO}_{2}$ of $5 \mathrm{vol} \%, \mathrm{H}_{2} \sim 50 \mathrm{vol} \%$ and $\mathrm{H}_{2} \mathrm{~S} 3000$ ppm to make sure a syngas GHSV of $10000 \mathrm{~h}^{-1}$. It should be noted that the composition of industrial syngas as raw materials to SWGS plants does vary a lot due to many issues, such as the coal type, employed gasifiers and the exact gasifying technologies [21-23]. The syngas composition employed in this research, especially the CO content has considered the suggestions from field experts, plant designers, and more importantly the practical $\mathrm{CO}$ vol\% of several representative commercialized gasifications (typical slurry feed entrained-flow gasifier, e.g., Chevron Texaco Gasifier, gives $30-45$ vol\% CO; dry feed entrained-flow gasifier, e.g., Shell Gasifier, may give CO percentage of $\sim 60 \mathrm{vol} \%$ ) [22-25]. In order to extend the catalytic lifetime for deactivated samples and for a safety consideration, industrial $3 \mathrm{Mp}$ pressure was not employed and all samples were tested under atmosphere pressure; however, as the reaction is volume constant, the current system causes very limited discrepancy in the catalytic property evaluations.

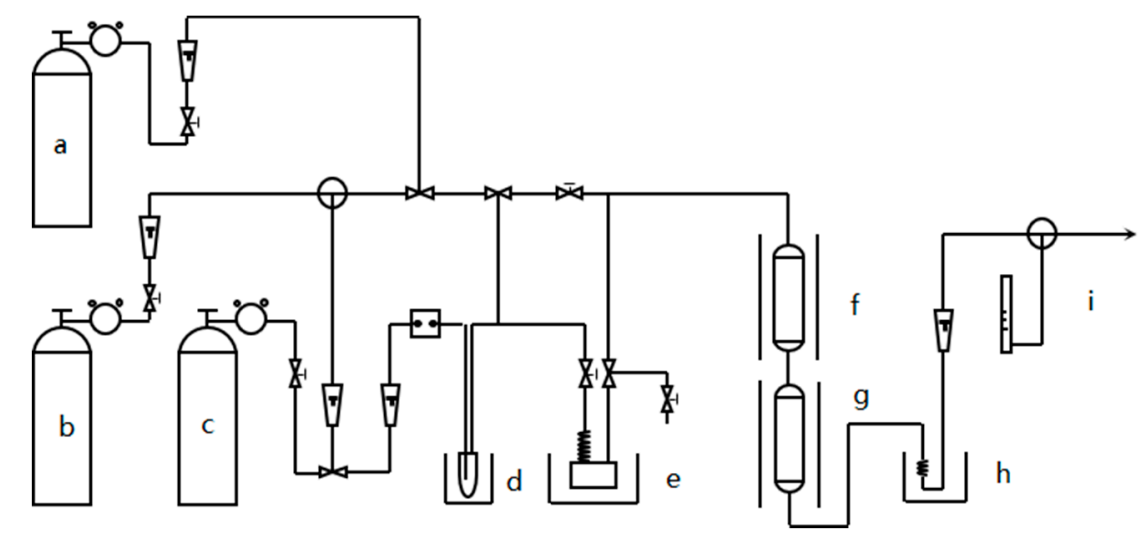

Figure 2. System of laboratory SWGS test: (a) $\mathrm{N}_{2}$ for catalyst stabilization (b) Dry gas; (c) $\mathrm{N}_{2}$; (d) evaporator 1; (e) evaporator 2; (f) reactor 1; (g) reactor 2; (h) gas-liquid separator; (i) outlet to GC.

Catalytic performances of different samples at three temperature points $\left(265^{\circ} \mathrm{C}, 350{ }^{\circ} \mathrm{C}\right.$ and $\left.450{ }^{\circ} \mathrm{C}\right)$ are presented in Figures 3 and 4, respectively. At each temperature, the catalyst samples were stabilized in $\mathrm{N}_{2}$ for $1 \mathrm{~h}$ ahead of test. The reactor outlet flow was analyzed with on-line gas chromatography 
(Agilent 7890, packed column $1.5 \mathrm{~m} \Phi 3 \mathrm{~mm}$, TCD, FID and FPD). The catalytic performance was measured by CO conversion:

$$
\begin{gathered}
\mathrm{X}_{\mathrm{CO}} \%=\left(\mathrm{Y}_{\mathrm{CO}}^{0}-\mathrm{Y}_{\mathrm{CO}}\right) /\left(\mathrm{Y}_{\mathrm{CO}}^{0}\right) \times 100 \\
\mathrm{Y}_{\mathrm{CO}}^{0}-\mathrm{CO} \text { inlet vol\%; } \mathrm{Y}_{\mathrm{CO}}-\mathrm{CO} \text { outlet vol } \%
\end{gathered}
$$

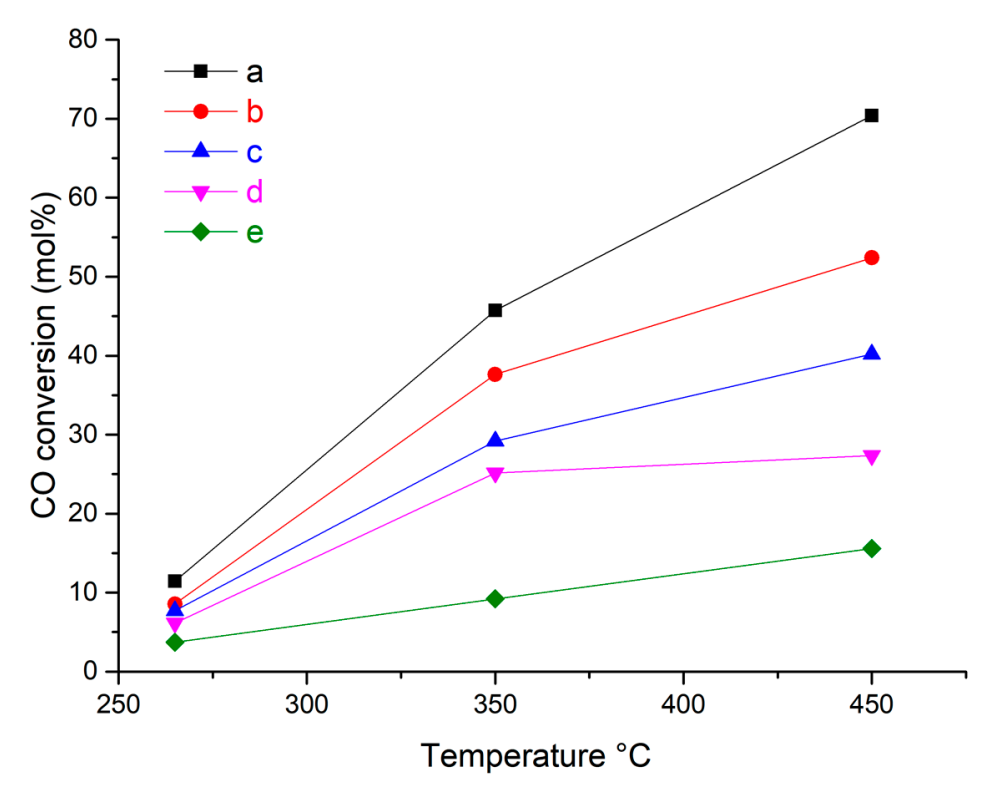

Figure 3. Laboratory test of $\mathrm{CO}$ conversion achieved by CATs served in industry for different years: (a) CAT as-prepared; (b) 1 year served; (c) 2 years served; (d) 3 year served; (e) 4 years served.

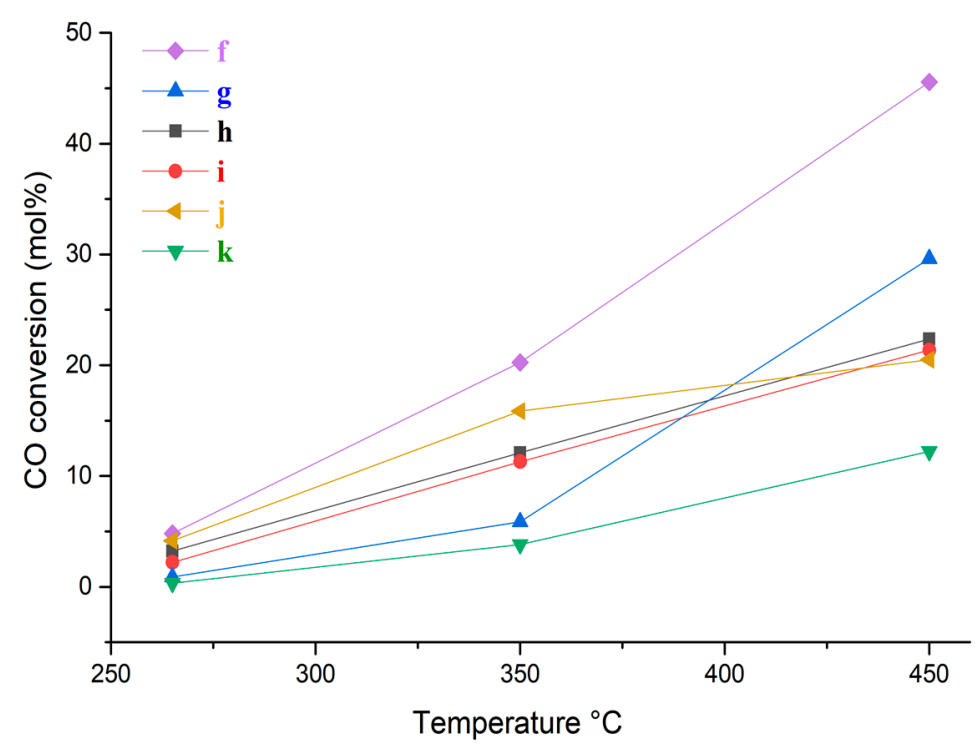

Figure 4. Laboratory test of CO conversion achieved by CATs deactivated for different reasons: (f) As poisoned; (g) caking 1; (h) water soaking; (i) caking 2; (j) Cl poisoned; (k) sintering by hot spot.

It is clearly shown in Figure 3, longer-time served CAT always led to a lower CO conversion in the same laboratory experiment, which is an intuitionistic sign of catalyst 'aging to deactivate'. All samples exhibited very low $\mathrm{CO}$ conversion at $265^{\circ} \mathrm{C}$ which implies a higher temperature is required for the sufficient catalytic activation. At $450{ }^{\circ} \mathrm{C}$, all samples achieved $\mathrm{CO}$ conversion of $10 \mathrm{~mol} \%$ or much higher $(70 \mathrm{~mol} \%)$. Interestingly, $\mathrm{CO}$ conversion at $350{ }^{\circ} \mathrm{C}$ showed a huge difference between samples 
used for 3 and 4 years, while at $450^{\circ} \mathrm{C}$, the difference between these two samples was less. To answer the above question, two notes could be addressed: 1) $310-450{ }^{\circ} \mathrm{C}$ is the proper temperature range of industrial High-Temperature WGS (HTS). For HTS, a higher temperature, i.e., $450^{\circ} \mathrm{C}$, possesses more influence on the reaction rate, which could minimize the actual $\mathrm{CO}$ conversion difference between differently aged catalysts especially in a stream reactor ( ${ }^{*}$ It should be noted that raising catalyst bed temperature is a common way to extend the lifetime of less catalytic, aged catalysts in the chemistry industry although coke formation may also be fastened at the same time) $[1,4,12,16,18]$. 2) WGS at $350{ }^{\circ} \mathrm{C}$ or below relies more on the reserved intrinsic properties of the employed catalyst, thus, the poorer performance of 4 years served CAT was amplified. The above results support recent studies focusing on the development of a lower temperature WGS catalyst; the aim of such exploration is to speed up catalytic performance at $300{ }^{\circ} \mathrm{C}$ or lower while taking the advantage of WGS reaction equilibrium (WGS process is moderately exothermic) [1,6-8].

In Figure 4, a series of CAT samples accidentally deactivated were evaluated. We carefully selected samples from several large scale Coal-to-Methanol/Liquid oil/Hydrocarbons industrial plants to make sure they are referential. Except one sample deactivated by caking $\left(\sim 45 \mathrm{~mol} \% \mathrm{CO}\right.$ conversion at $\left.450{ }^{\circ} \mathrm{C}\right)$, most of them were not completely deactivated but quite close to the status of CAT 3-4 years served. Their morphology was presented by scanning electron microscopy (SEM) as shown in Figure 5.

Caking is an early-stage deactivation of alumina-based catalysts serving for years due to which the catalyst particles became loose (not very obviously), further compressed or agglomerated. A general reason for caking could be the high-pressure hydrothermal working conditions, e.g., 3 Mpa for SWGS. As caking is a more 'physical' property change, no obvious morphological difference was found between CATs used for 4 years (Figure 5a), CATs used for 3 years (Figure 5b), CATs deactivated by caking 1 (Figure 5c) and CATs deactivated by caking 2 (Figure $5 \mathrm{~d}$ ). Water soaking accidently occurs between the WGS plant operating cycles. There are various reasons for the local enrichment of water/steam in a WGS plant, which leads to the catalyst surface being oversaturated with $\mathrm{H}_{2} \mathrm{O}$ which could be another important reason for catalyst caking. From SEM results (Figure 5e), the water-soaked CATs showed very similar morphology as compared to CATs served for years or caked, with only a small difference on the catalyst surface (more obviously seen in Figure 5e3, the surface of CATs presented special 'washing' appearance). CATs deactivated by sintering exhibited the worst catalytic performance (Figure $4 \mathrm{k}$ ) in terms of the lowest $\mathrm{CO}$ conversions at the selected three temperatures, indicating the most severe damage of catalytic sites. This is more evidenced by the SEM results (Figure 5f); the apparent crystallization reflected in the picture brought in the dramatic and irreversible reducing of catalyst surface and active sites. It should be mentioned that there were in fact very unusual catalyst deactivations by 'poisoning' in which case poisonous elements (e.g., As and $\mathrm{Cl}$ ), even in very small amounts, deposited over the catalyst surface (Figure 6). By far, no strong links were found between the cause of WGS deactivation and the above catalyst poisoning. Such accident rarely occurred and could be attributed to the unsuccessful coal preparation before gasification.

More information about the surficial elemental compositions of different samples are listed in Tables 2 and 3. Trends have been found for the 1-4 years served CATs. Fresh (as-prepared) CAT possessed the highest Mo level and Al level, which fell gradually as the serving years increased. The 1 year served CAT became sulfurized, then the sulfur level decreased at a faster rate than Mo and Al. As more Mo elements were continuously lost from the catalyst surface, the surface level (concentration) of Co elements accordingly increased implying they were comparably more stable in the LSGRT SWGS process. No $\mathrm{Cl}$ or As was observed on the surface of as-prepared CAT, but their concentrations went up gradually with the time on stream of WGS increasing. For the industrial SWGS process, it was difficult to completely avoid the accumulation of unexpected poisoning elements over the catalyst surface especially during a long-time plant running. 

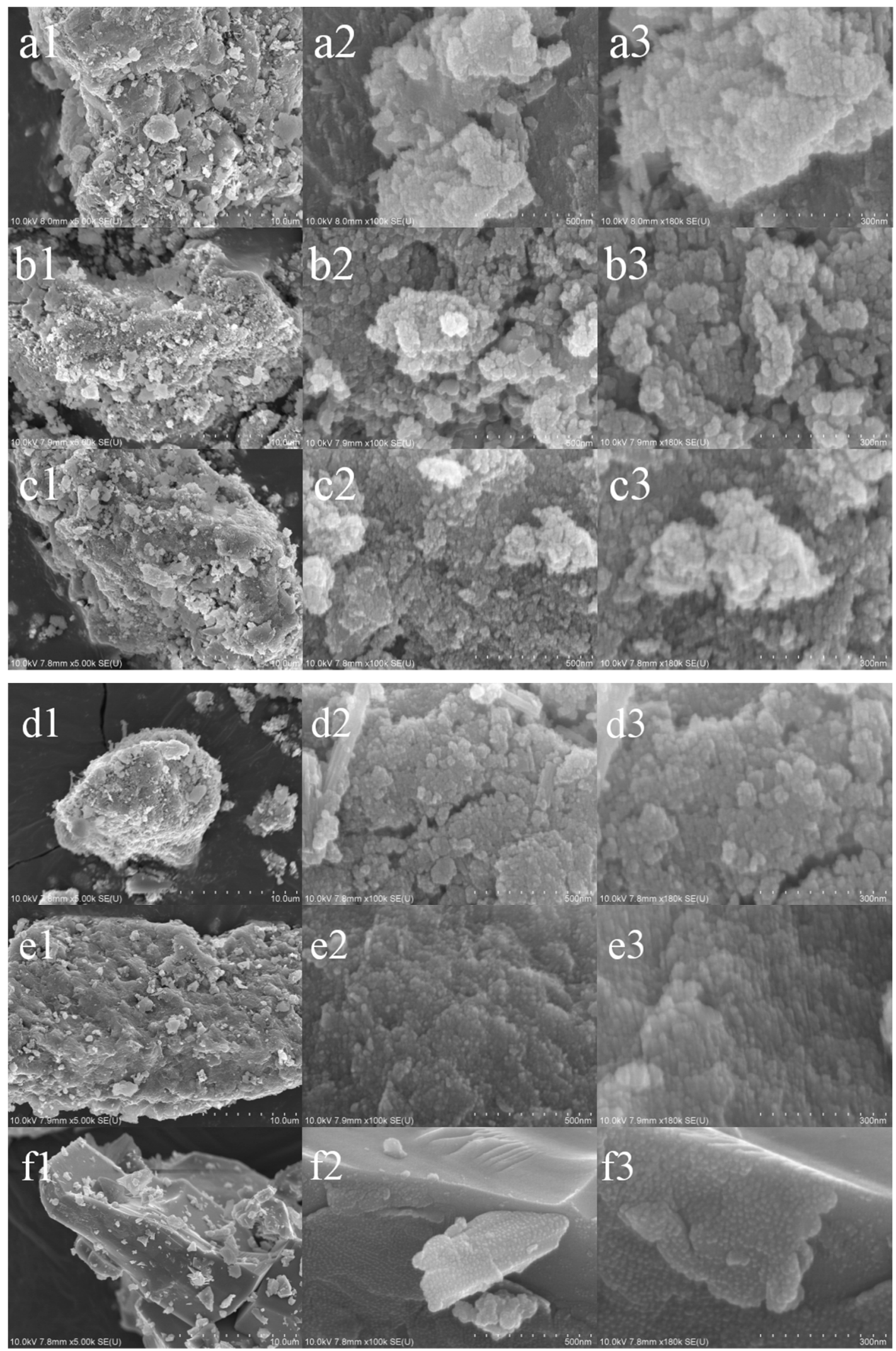

Figure 5. SEM images of CATs unloaded after time on stream for 3-4 years or deactivated for other reasons: (a) 4 years; (b) 3 years (c) caked 1; (d) caked 2; (e) water soaked (f) sintered. 

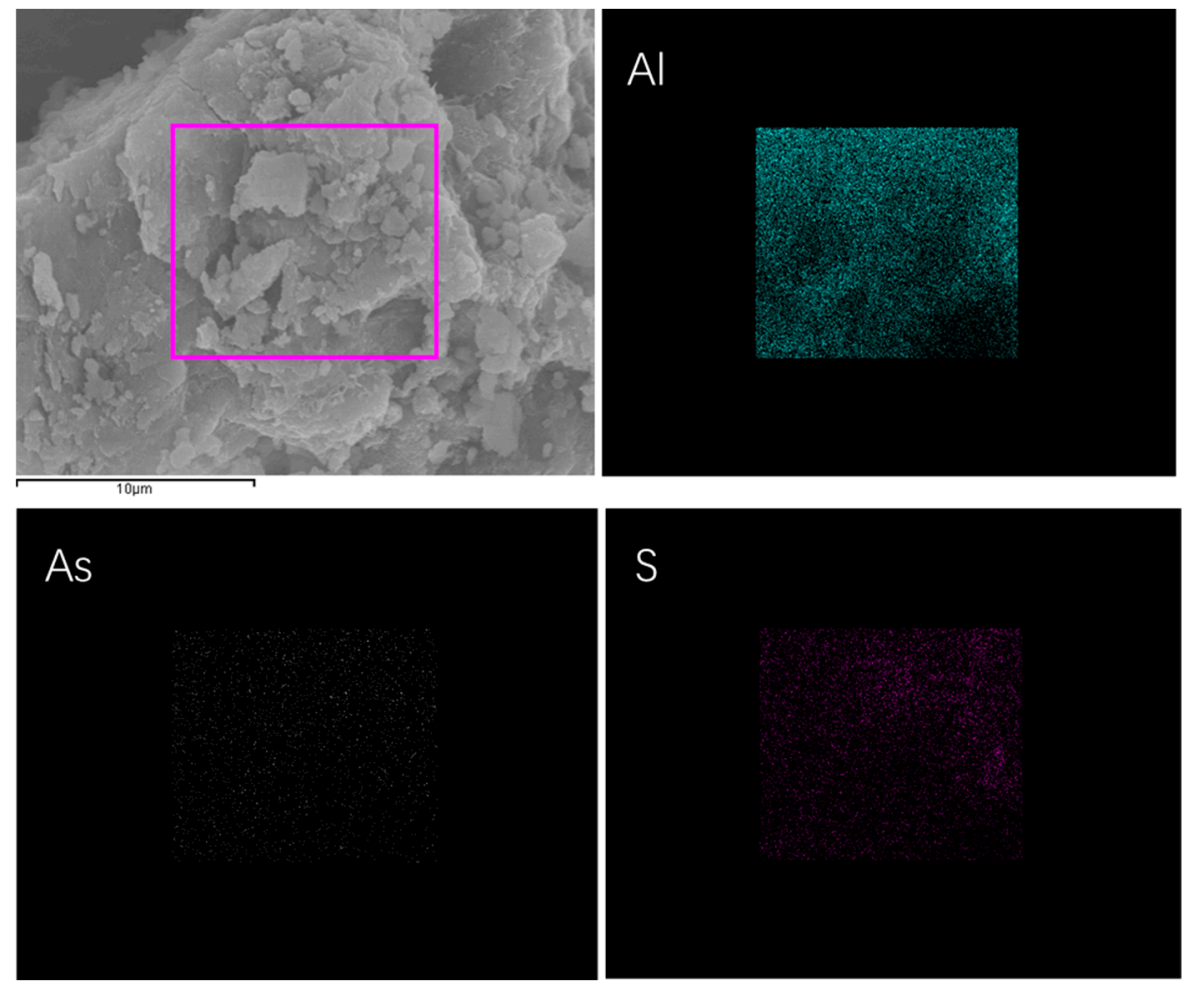

(a)
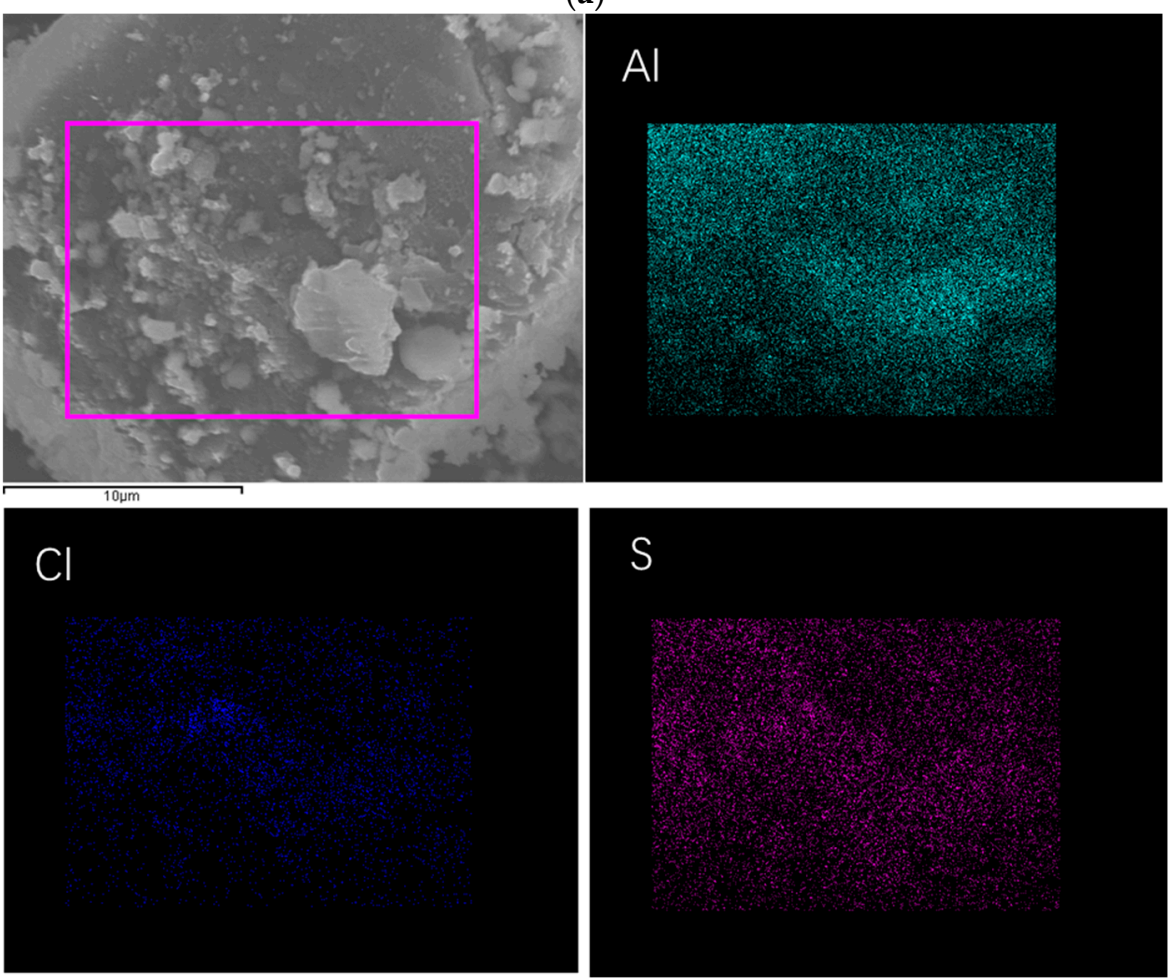

(b)

Figure 6. Elemental mapping results of CATs poisoned by $\mathrm{As}(\mathbf{a})$ and $\mathrm{Cl}(\mathbf{b})$.

$\mathrm{CaO}$ was introduced in the preparation of CAT as a common method to improve the catalyst mechanical strength. As shown in Table 2, even in a very small amount, Ca content over the catalyst surface fell gradually with time on stream extending. However, as shown in Table 3 , the sintered CAT and caked CATs exhibited much higher Ca levels than all other samples. The accumulation of Ca over CAT surface might be a direct reason of catalyst particle growth and aggregation, which led to 
the final deactivation by caking $[12,26,27]$. In some cases, the slow caking of catalyst particles could be accelerated by high temperatures and finally evolved to the sintering deactivation: 1) The WGS reaction is exothermic, more exothermic is due to higher accompanied methanation side reaction which might occur at aggregated catalyst particles causing locally over-heated sites (hot spot). 2) The local high temperature further accelerates the metal particle growth and finally the aggregation (sintering). 3) The observed high Ca levels of caked and sintered samples supported the above explanations.

Table 2. Elemental distributions of different CATs (fresh-used), the standard deviation of the measured value is set as unity in the last decimal.

\begin{tabular}{cccccc}
\hline Composition & CAT & 1 year & 2 years & 3 years & 4 years \\
\hline $\mathrm{Mo}\left(\mathrm{MoO}_{3}\right)$ & 7.856 & 6.905 & 6.885 & 6.803 & 6.628 \\
$\mathrm{Co}\left(\mathrm{Co}_{3} \mathrm{O}_{4}\right)$ & 1.985 & 1.898 & 2.326 & 2.659 & 3.436 \\
$\mathrm{Al}\left(\mathrm{Al}_{2} \mathrm{O}_{3}\right)$ & 75.349 & 73.334 & 71.005 & 70.804 & 68.801 \\
$\mathrm{~S}\left(\mathrm{SO}_{3}\right)$ & 0.222 & 16.015 & 13.309 & 10.315 & 9.655 \\
$\mathrm{Ca}(\mathrm{CaO})$ & 0.582 & 0.565 & 0.456 & 0.408 & 0.249 \\
$\mathrm{Cl}(\mathrm{Cl})$ & 0 & 0.22 & 0.203 & 0.237 & 0.274 \\
$\mathrm{As}\left(\mathrm{As}_{2} \mathrm{O}_{3}\right)$ & 0 & 0.01 & 0.01 & 0.01 & 0.028 \\
$\mathrm{C}($ Organic $)$ & 0 & 0.022 & 0.035 & 0.05 & 0.063 \\
\hline
\end{tabular}

Table 3. Elemental distributions of different CATs deactivated by other reasons, the standard deviation of the measured value is set as unity in the last decimal.

\begin{tabular}{llllll}
\hline Composition. & Caked 1 & Caked 2 & Sintered & $\mathbf{C l}$ & As \\
\hline $\mathrm{Mo}\left(\mathrm{MoO}_{3}\right)$ & 8.323 & 8.571 & 9.216 & 6.905 & 6.322 \\
$\mathrm{Co}\left(\mathrm{Co}_{3} \mathrm{O}_{4}\right)$ & 2.865 & 2.015 & 1.893 & 1.934 & 1.751 \\
$\mathrm{Al}\left(\mathrm{A}_{12} \mathrm{O}_{3}\right)$ & 70.085 & 72.86 & 69.008 & 60.104 & 71.521 \\
$\mathrm{~S}\left(\mathrm{SO}_{3}\right)$ & 10.223 & 9.05 & 8.61 & 14.732 & 9.772 \\
$\mathrm{Ca}(\mathrm{CaO})$ & 0.603 & 0.721 & 0.859 & 0.228 & 0.303 \\
$\mathrm{Cl}(\mathrm{Cl})$ & 0.15 & 0.215 & 0.429 & 0.725 & 0.642 \\
$\mathrm{As}\left(\mathrm{As}_{2} \mathrm{O}_{3}\right)$ & 0.01 & 0.01 & 0 & 0.05 & 0.101 \\
$\mathrm{C}($ Organic $)$ & 0.037 & 0.082 & 0.097 & 0.052 & 0.041 \\
\hline
\end{tabular}

All unloaded CATs showed different levels of carbon deposition over the catalyst surfaces as a straightforward evidence of coking deactivation. However, even the sintered CAT and caked CATs have more cokes; coke formation was still not regarded as the main reason for WGS deactivation; a possible reason could be the $\mathrm{H}_{2}$ generated in the WGS reaction suppressed the development of catalyst coking.

Crystal structures of different samples were analyzed with X-ray diffraction (XRD) as shown in Figures 7-9. The sharper diffraction peaks of $\gamma-\mathrm{Al}_{2} \mathrm{O}_{3}$ in Figure 7 indicate all CATs served for different years have developed further crystalized alumina structures as compared with fresh CAT, which is a common result for alumina supported catalysts long-term served with steam. Diffraction (a peak at $\sim 61^{\circ}$ ) from the 008 plane of crystal $\mathrm{MoS}_{2}$ was clearly observed on the 1 year served CAT, as an early sign of the irreversible loss of mono-layer dispersed $\mathrm{MoS}_{2}$ which is the active sites for catalytic CO conversion [28]. Diffractions from the 105 plane (a peak at $\sim 50^{\circ}$ ) and 002 plane (a peak at $\sim 14^{\circ}$ ) of crystal $\mathrm{MoS}_{2}$ were continuously found on CATs served for 3 years and 4 years [28]. The above results reflected an evolution of the $\mathrm{MoS}_{2}$ phase supported on CAT when served in the industrial WGS plant under a lean steam/gas ratio, which is supposed to start from a mono-layer distribution and gradually develop into a complex crystal structure. Crystal phases of $\mathrm{CaMoO}_{4}$ and $\mathrm{MgAl}_{2} \mathrm{O}_{4}$ were also found to be present on all served CATs indicating an effective alkali modification.

By comparison (Figure 8), the crystallinity of $\gamma-\mathrm{Al}_{2} \mathrm{O}_{3}$ was noted to be less developed on $\mathrm{Cl}$ and As poisoned, caked and steam-soaked CATs, which is more similar to the as-prepared CAT. These observations match the fact that CATs in Figure 8 were not used for a long time due to the deactivation. On the other hand, these XRD observations also indicate caking, as the early stage of alumina supported 
catalyst blocking or sintering, did not show apparent impact on crystallization. Besides, crystal phases of boehmite (precursor of alumina support) were noted to be formed in the caked and $\mathrm{Cl}$ poisoned CATs all pointing to an undesired catalyst structure damage.

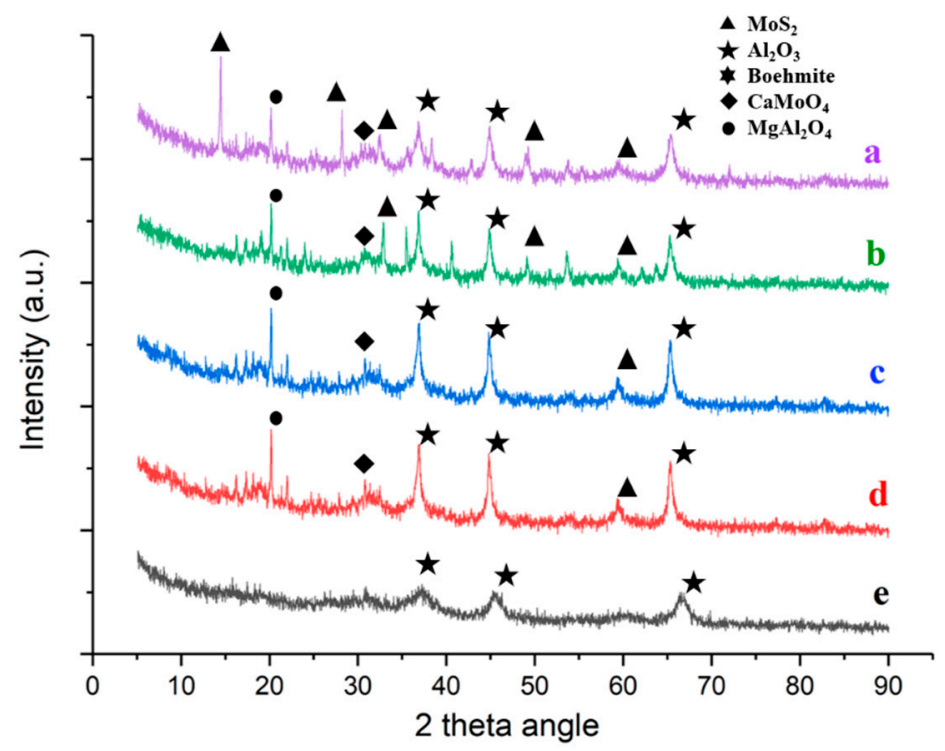

Figure 7. XRD patterns of CATs served for different time (a) 4 years; (b) 3 years; (c) 2 years; (d) 1 year; (e) as-prepared.

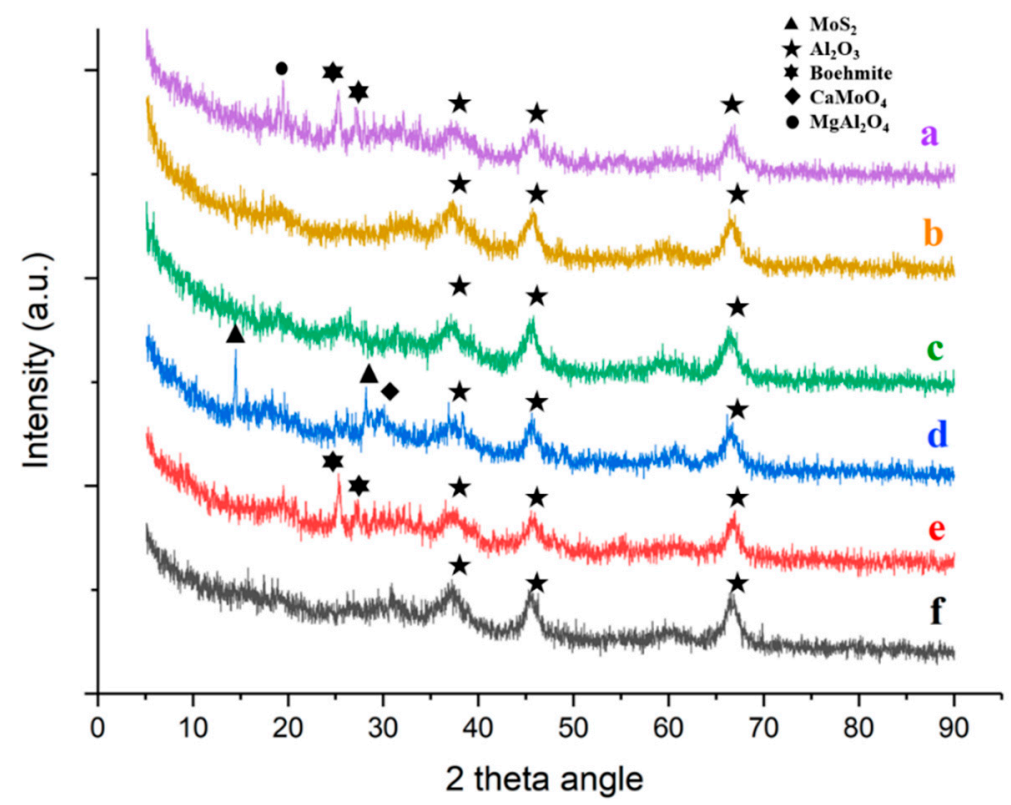

Figure 8. XRD patterns of CATs deactivated for different reasons $(\mathbf{a}) \mathrm{Cl}$; (b) As; (c) caking 1 ; (d) caking 2 ; (e) steam-soaked; (f) as-prepared.

In operating catalyst beds both sintering and caking could lead to block formation or aggregation of alumina supported catalyst. However, as seen in our results (Figure 9), for CATs served in LSGRT SWGS, only sintering leads to very distinguished and complicated crystalline structures. This is further supported by our SEM images (Figure 5f) since the crystallization of sintered CATs is so apparent and uncontested. In Figure 8 we also noted the formation of crystallized $\mathrm{MoS}_{2}$ on the caked CAT sample 
(Figure 8d, caking 2), which implies that caking might be another reason leading to the loss of mono layered $\mathrm{MoS}_{2}$ and, therefore, the dramatic reduction of catalytic sites for SWGS.

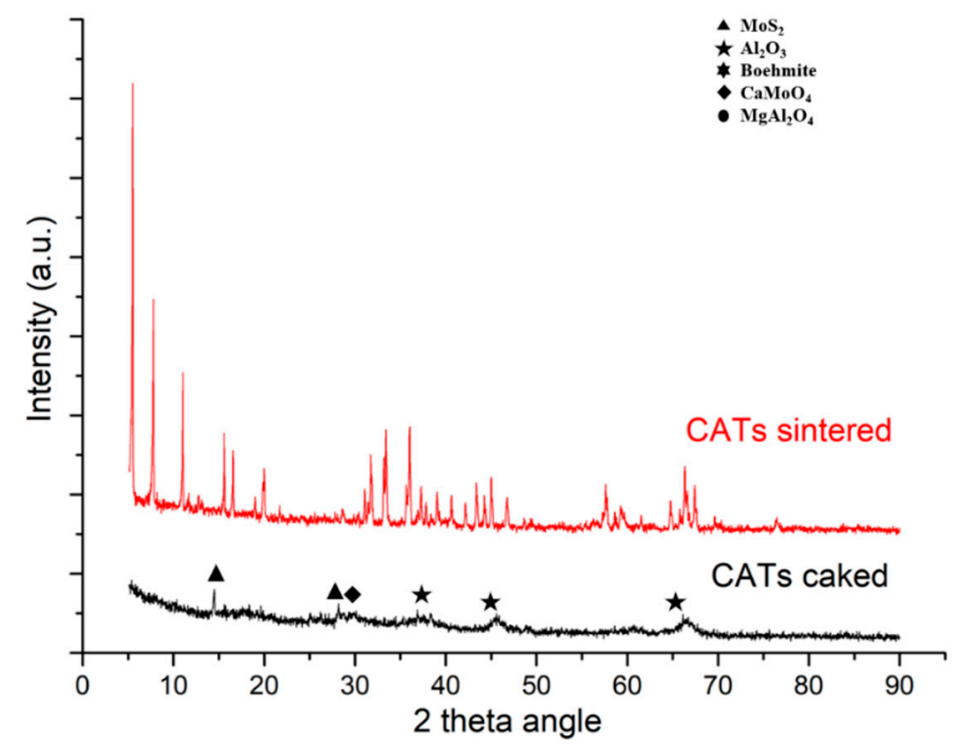

Figure 9. XRD patterns of CATs deactivated by sintering vs. by caking 2 .

For further analyses, Raman spectroscopy (Figure 10) is employed to draw the surficial properties of different CATs. $\mathrm{MoO}_{3}$ species (Raman shifts at $\sim 320, \sim 910$ and $1050 \mathrm{~cm}^{-1}$ ) are only observed on the as-prepared (un-sulfurized) CAT. All served CATs have formed $\mathrm{MoS}_{2}$ species on their surface as clearly evidenced by the featured Raman shifts at $\sim 380$ and $\sim 410 \mathrm{~cm}^{-1}$, respectively. The $\mathrm{MoS}_{2}$ signals gradually drop as the serving time of CAT increases. Both the loss of sulfur contents and the $\mathrm{MoS}_{2}$ crystallization could lead to a reduced $\mathrm{MoS}_{2}$ catalyst surface dispersion in a long term SWGS process, which can be reflected by the gradually weakened $\mathrm{MoS}_{2}$ Raman signals.
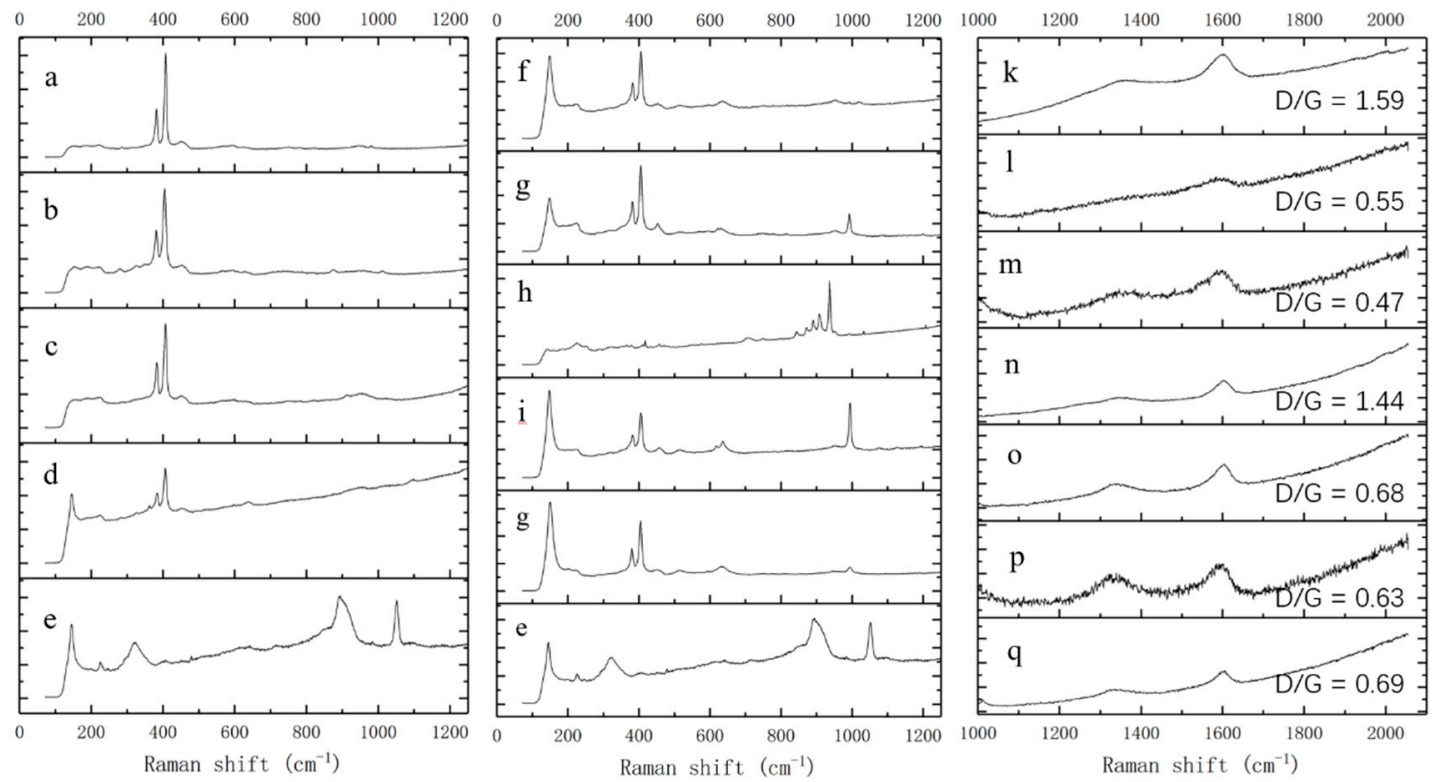

Figure 10. Laser Raman spectra of CATs at different status and coke formations (a) served 1 year; (b) served 2 years; (c) served for 3 years; (d) served for 4 years; (e) as-prepared; (f) caked; (g) water soaked; (h) sintered; (i) Cl; (g) As; (k) coke-caked; (1) coke-water soaked; (m) coke-sintered; (n) coke-served for 4 years; (o) coke-served for 3 years; (p) coke-served for 2 years; (q) coke-served for 1 year. For D/G ratio the standard deviation of the measured value is set as unity in the last decimal 
Caked, Cl-poisoned, As-poisoned CATs also exhibit clear $\mathrm{MoS}_{2}$ signals in a strong contrast to the sintered CAT which shows only very faint $\mathrm{MoS}_{2}$ Raman bands. For the sintered CAT, a group of unidentified Raman shifts between 800 and $950 \mathrm{~cm}^{-1}$ are observed possibly attributed to the complex interactions between catalyst surface Mo species. Raman shifts between 140 and $150 \mathrm{~cm}^{-1}$ only present in the spectra of as-prepared CAT, 4 years served CAT, and those accidentally deactivated CATs (except sintered CAT). A possible reason could be the variational interactions between the catalyst surface Mo species and support alumina; on the other hand, these signals might be part of the background when there is very weak $\mathrm{MoS}_{2}$ signal. Notably, Cl-poisoned, As-poisoned and water-soaked CATs also exhibited Raman shift of $\mathrm{MoO}_{3}$ at $\sim 1050 \mathrm{~cm}^{-1}$. It is assumed that for these CATs, the sulfurization of $\mathrm{MoO}_{3}$ was unpredictably disturbed.

Carbon bands (the D peak around $1350 \mathrm{~cm}^{-1}$ and the $G$ peak around $1580-1600 \mathrm{~cm}^{-1}$ ) are also clearly detected by Laser Raman for the caked CAT, water-soaked CAT, sintered CAT and served CATs (Figure $10 \mathrm{k}-\mathrm{q}$ ). The $\mathrm{D} / \mathrm{G}$ ratio of carbonaceous species was calculated for each sample to describe the extent of carbon formation $[29,30]$. The $D / G$ ratio lies between 0.6 and 0.7 for CATs served for 1-3 years indicating a comparably uniform carbonaceous distribution on the catalyst surface. The 4 years served CAT possesses more diamondlike (DLC) carbons of $\mathrm{SP}_{3}$ bonding which also implies that more hydrogen contents could exist in the deposited carbon compounds. Unlike carbon deposition obtained in a zeolite catalyzed acidic reaction, where the catalyst surface carbonaceous species are normally deeply dehydrogenated, the WGS reaction generates rich amounts of $\mathrm{H}_{2}$ with steam which might possess an inverse role to hydrogenate the cokes. The $D / G$ ratio of accidentally deactivated CATs varies in the range of 0.47-1.59; the exact reason may require a future investigation with the help of catalyst accidental deactivation simulation in laboratory conditions. Infrared spectroscopy was employed as a complement to the above Raman studies where comparisons were made with the previous IR studies on supported $\mathrm{MoS}_{2}$ catalysts or others [31,32]. As seen in Figure 11, the as-prepared CAT without sulfur presented apparently divergent spectra in a stark contrast to the served, sulfurized CATs; for this sample (Figure 11a) IR bands only appeared at 1600, 1380, 1280 and $1000 \mathrm{~cm}^{-1}$. The above bands (IR peaks) became eroded $\left(1380,1280\right.$ and $\left.1000 \mathrm{~cm}^{-1}\right)$ or slightly shifted $\left(1600 \mathrm{~cm}^{-1}\right)$ in the spectra of served CATs, as a good sign of sulfurization. Meanwhile, new bands at 1450, 1100 (there was even a small peak at $1050 \mathrm{~cm}^{-1}$ in the spectra of CAT served 1 year which was 'just sulfurized' compared with the other 3 served CATs) and $890 \mathrm{~cm}^{-1}$ appeared; the first two bands were so strong in the spectra that could be a most straightforward evidence showing the occurrence of successful sulfurization. As the serving years of CAT increased (Figure $11 \mathrm{~b}-\mathrm{e}$ ), the bands at 1450 and $1100 \mathrm{~cm}^{-1}$ became gradually weakened with the WGS catalytic ability accordingly lowered; the $1450 \mathrm{~cm}^{-1}$ band completely disappeared in the spectra of 4 years served CAT which was the most severely served CAT.
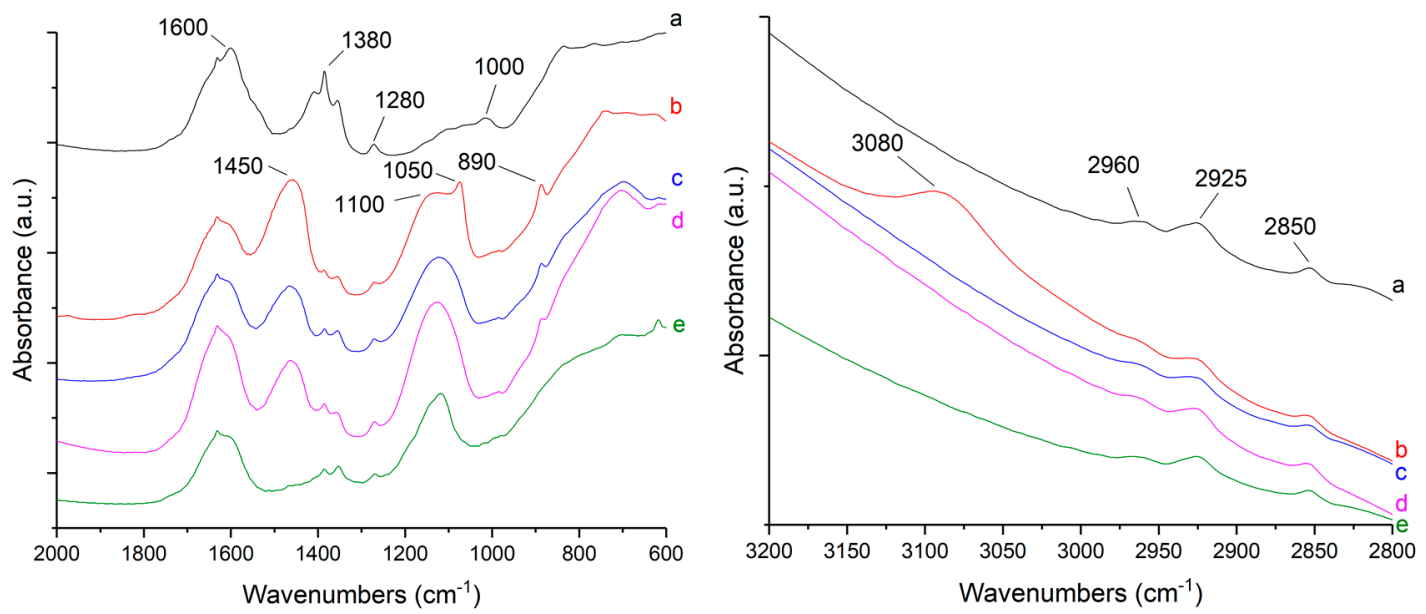

Figure 11. FT-IR spectra of CATs used for different years (a) as-prepared; (b) served for 1 year; (c) served for 2 years; (d) served for 3 years; (e)served for 4 years. 
In the spectra of accidently deactivated CATs, 1450 and $890 \mathrm{~cm}^{-1}$ (there was a shift to $840 \mathrm{~cm}^{-1}$ in the spectra of sintered CATs) bands were still missing; however, the band at $1100 \mathrm{~cm}^{-1}$ was clearly shown despite that signals were much weaker for the As-poisoned CAT (Figure 12f).
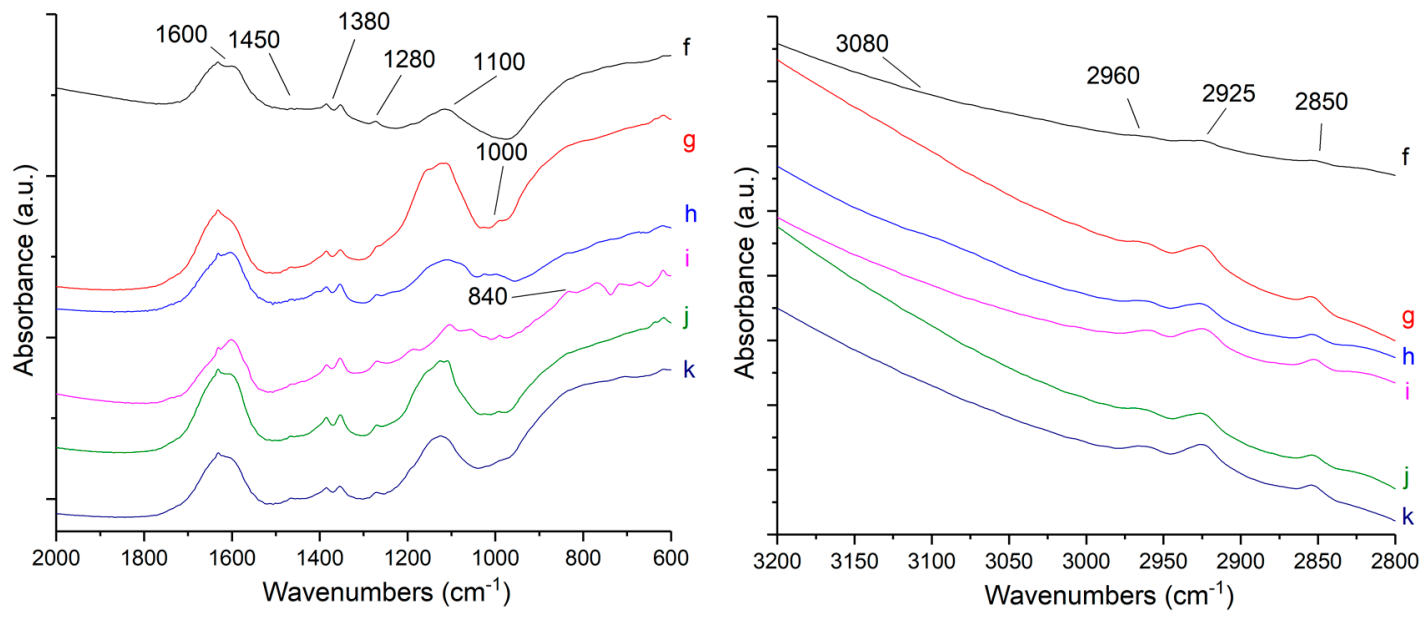

Figure 12. FT-IR spectra of CATs deactivated for different reasons (f) As; (g) Cl; (h) water soaked; (i) sintered; (j) caked 1; (k) caked 2.

Despite the poor resolution in coke analysis, for each sample attempts were also made to capture the possible IR bands of carbonaceous compounds deposited. However, in the commonly used coke domains both aromatic $\mathrm{CH}$ stretching modes $\left(2800-3200 \mathrm{~cm}^{-1}\right)$ and paraffinic carbon $\mathrm{CH}$ stretching modes (3000-3200 $\mathrm{cm}^{-1}$ ) were not confidentially detected, whereas the observed bands at 2850, 2925, 2960 and $3080 \mathrm{~cm}^{-1}$ are possibly attributed to the catalyst support frameworks [30].

The above IR discussions indicated that CATs in a good sulfurized condition mainly possessed two bands at 1450 and $1100 \mathrm{~cm}^{-1}$, respectively. Both bands might be responsible for the effective sulfur tolerant WGS. However, only the change of $1450 \mathrm{~cm}^{-1}$ band was noted more sensitive for those deactivated CATs, and therefore, it is more important to assess the remaining catalytic properties. Notably, this new finding was not reported in the previous studies of high steam/gas ratio sulfur tolerant WGS. Compared with the IR results, although more intensive in signals, Raman spectra only indicated an overall reduction of catalyst surface $\mathrm{MoS}_{2}$ species on the deactivated CATs (Raman shifts at $\sim 380$ and $\sim 410 \mathrm{~cm}^{-1}$ ).

\section{Experimental}

The CAT samples (Figure 13) were precisely unloaded from the plant and packed in vacuum at the same time. CATs served 1-4 years (Figure $13 \mathrm{c}-\mathrm{f}$ ) were selected, and all accidentally deactivated CATs (Figure 13 g-1) only served for less than two years.

Experimental sets employed for laboratory sulfur tolerant WGS reaction over selected CATs were discussed in the above.

Scanning electron microscopy (SEM) were taken with a JEOL 840F scanning microscope instrument (JEOL, Peabody, USA). Elemental mapping employed a GeminiSEM 300 scanning microscope instrument (Zeiss, Jena, Germany). Samples were deposited onto dust free platform and treated with gold-spray to enhance the signal before analysis.

X-ray diffraction results were obtained with a PANalytical X'Pert PRO diffractometer (Malvern Panalytical, Royston, UK) using $\mathrm{Cu} \mathrm{K} \alpha 1$ radiation in diffraction angle from $5^{\circ}$ to $90^{\circ}$ (2 theta angular range) and a scan rate of $0.8^{\circ} \mathrm{min}^{-1}$ in $2 \theta$.

Laser Raman spectra were recorded with a Perkin-Elmer Raman Station 400F Raman Spectrometer (Perkin Elmer, Waltham Mass, USA). Raman shifts were recorded between $50 \mathrm{~cm}$ and $1250 \mathrm{~cm}^{-1}$ for all CATs or 1000 and $2050 \mathrm{~cm}^{-1}$ for selected coked CATs. Powder samples were hold with a piece of clean 
glass during scan. For D/G ratio calculation LapSpec (Version 5.58, Horiba, Kyoto, Japan) software was used in the peak matching and integration (Gaussian method).

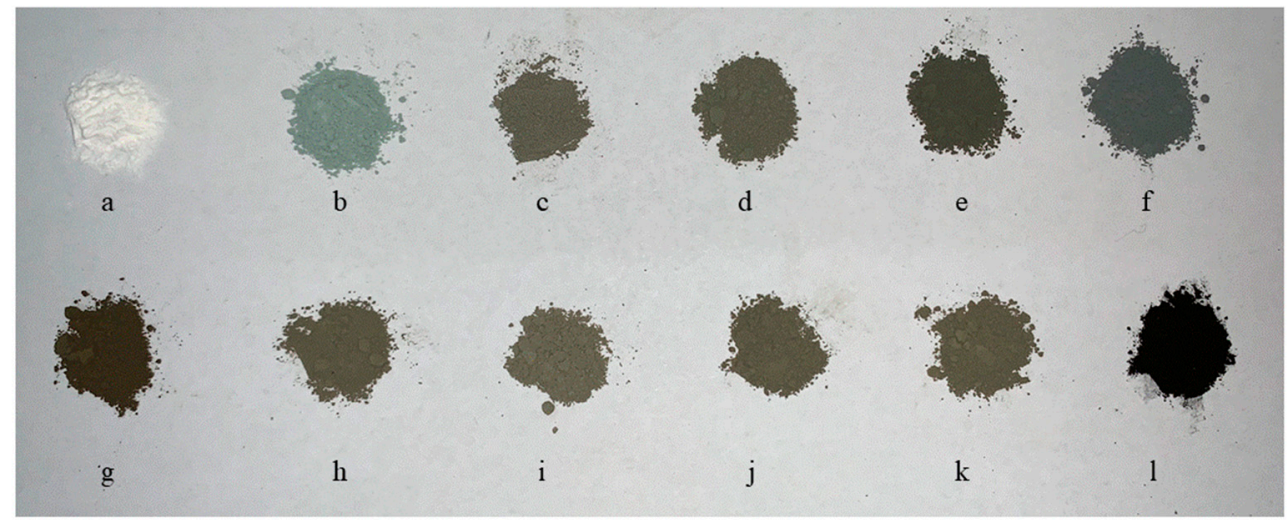

Figure 13. CATs samples investigated (samples in photo were broken into powders for characterizations): (a) $\gamma-\mathrm{Al}_{2} \mathrm{O}_{3}$; (b) as-prepared; (c) 1 year served; (d) 2-years served; (e) 3-years served; (f) 4-years served; (g) As; (h) Cl; (i) water-soaked; (j) caked 1; (k) caked 2; (l) sintered.

Infrared spectra were obtained by a Bruker Tensor II FTIR spectrometer (Bruker, Santa Barbara, USA) in the wavenumber range of $4000-400 \mathrm{~cm}^{-1}$. Samples were mixed with $\mathrm{KBr}$ (sample/ $\mathrm{KBr}=1: 50$ in weight) and then pressed into pellets for measurements.

\section{Summary}

The latest development in sulfur-tolerant water gas shift catalysts and its application in low/lean steam/gas ratio technology (LSGRT) in industrial operation were comprehensively reported in this work. LGSRT possessed many improvements as compared with the traditional high steam/gas ratio technology. The LSGRT catalyst does not need extra steam adding in the WGS process; it just requires adding liquid water directly to the raw syngas stream to effectively control the hot spot and reduce the energy input. This can also help to control the WGS reaction depth, as well as the suppression of methanation side reactions.

Catalysts based on Mo-Co/alkali/ $\mathrm{Al}_{2} \mathrm{O}_{3}$ composition were successfully developed and applied to the LSGRT water gas shift process, and a series of industrial samples (CATs) used under different conditions and lifetime stage were collected, laboratory tested and characterized with the techniques of XRD, SEM and Laser-Raman.

From the above works, many important findings were made: 1) The CO conversion of $\mathrm{Mo}-\mathrm{Co} /$ alkali/ $\mathrm{Al}_{2} \mathrm{O}_{3}$ catalyst (CATs in the above discussions) gradually fell after 1-4 years time on stream under the conditions of LSGRT while the difference between medium temperature $\left(350^{\circ} \mathrm{C}\right)$ and high temperature $\left(450^{\circ} \mathrm{C}\right)$ catalytic performances became less as the catalyst was being used. 2) Caking, water-soaking and sintering led to negative effects on the catalytic performance of LSGRT catalysts, whereas sintering gives the most severe damage to catalyst in terms of changes in catalyst crystal structure and surface properties as reflected by the characterizations. 3) $\mathrm{Cl}$ and As could be poisonous for LSGRT catalysts and were supposed to disturb the catalyst sulfurization. On the other hand, water-soaking might also lead to a similar result. 4) New spectroscopy evidence was found in the characterizations of served and deactivated LSGRT SWGS catalysts which together with the above experimental results could be a good reference for researchers and industry.

\section{Expanded Discussion}

Even though LSGRT SWGS catalysts have been successfully employed in many important WGS plants in the past years, there is still an urgent demand for the continuous study and more tests, especially in the real field conditions. 
One would argue how the 'accidentally deactivated' samples discussed in this work could be representative for researchers and field experts; besides, these deactivation approaches might be random and therefore, the results only teach less. To make sure our results are representative and referential, one would apply their WGS catalyst under a similar condition, i.e., reaction with a lower steam/gas ratio; the accidental deactivations described in this work have encompassed as many originally unexpected deactivations as the catalyst inventers (part of our authors) could record, since the LSGRT SWGS catalysts were extensively applied:1) LSGRT SWGS catalyst in one plant could be accidentally caked, water-soaked, sintered, $\mathrm{Cl}$ poisoned or As poisoned; however, yet no other major reason was reported as newly found accidental deactivation. 2) One type of LSGRT SWGS catalyst accident could occur several times, or in different plants; however, these changes are significant deactivations. Although the exact mechanism of these accidental deactivations is not completely clear, we have given as much reliable explanations (e.g., a general reason for caking could be the high-pressure hydrothermal condition) as the current work could support and we do appeal for more researchers seeking future explorations.

Another discussion could be over a long time period in an environment that is lacking in the normal control which one would use in a lab setting, to which extent we could assure that something besides the operating conditions did not affect the LSGRT SWGS catalytic performance. This question points to not only WGS catalysts but also all other industrially employed catalysts, e.g., zeolites, as the amplification of catalytic performance from a laboratory reaction to industrial plant application does bring in many uncertainties. However, the potential risks could be effectively prohibited and controlled in many ways, such as rational catalytic design, long-term laboratory experiments, pilot test, the real monitoring of plants and more importantly, a continuous study on employed catalysts to further improve its performance $[33,34]$. While the practical WGS reaction occurring in a plant is a heterogenous, multi-direction process with several side reactions, e.g., methanation, it is first and foremost a chemical phenomenon that can be effectively controlled with the help of plant-integrated monitoring systems $[18,21]$. The above accidental deactivations may have not been found by the previous WGS laboratory studies, but observed and recorded by the practical plant monitoring; in this work, their significance on real WGS performance was firstly reported with a preliminary evaluation on the causes, which is of great importance to prohibit future deactivations and helps to effectively control plant operating conditions.

Author Contributions: For research articles with several authors, a short paragraph specifying their individual contributions must be provided. The following statements should be used "conceptualization, B.L. and Q.Z.; methodology, B.L., Q.Z. and T.X.; software, X.Z., J.Z. and F.W.; validation, L.Z. and Z.W.; formal analysis, B.L., L.Z., Z.W. and X.Z.; investigation, B.L., L.Z., Z.W., J.Z., Q.Z., and X.Z.; resources, J.Z. and Q.Z.; data curation, B.L., L.Z., Z.W., J.Z. and Q.Z.; writing-original draft preparation, B.L., T.X. and Q.Z.; writing-review and editing, B.L., Q.Z., Z.Z., J.G., and T.X.; visualization, B.L., X.Z. and F.W.; supervision, Q.Z., H.A., Z.Z., J.G. and T.X.; project administration, Q.Z. and J.G.; funding acquisition, B.L., Q.Z., H.A. and T.X.

Funding: The work was supported by the National natural science foundation of China youth program (NSFC code 21808241) and Shandong Provincial Key Research and Development Plan (code 2017CXGC1111).

Acknowledgments: We appreciate all the reviewers for their very useful and constructive comments. More appreciations are given to our group members at the China University of Petroleum (Beijing, China), and the oversea colleagues at the University of Oxford (Oxford, UK) and KACST (Riyadh, Kingdom of Saudi Arabia) for their contributions to the experiments and manuscript. The Industrial Engineering Laboratory of Sulfur Tolerant Water Gas Shift Catalyst subjected to China Petroleum and Chemical Industry Federation (CPCIF) is part of the Qingdao Lianxin Catalyst Company (China). The state Key Laboratory of Advanced Materials for Smart Sensing is a sub-department of General Research Institute for Nonferrous Metals (China). The industrial LSGRT SWGS catalysts were originally invented by Qingdao Lianxin Catalyst Company (China). Industrially served CATs and the as-prepared CATs were provided by the company. More importantly, they also kindly offered the practical plant running data (as the LSGRT SWGS catalyst supplier of those plants, Qingdao Lianxin Catalyst Company supervised and monitored the catalyst loadings as well as the practical plant runnings as part of their product services; data were collected for R\&D purposes). (J. Zhang and Q. Zong) from Qingdao Lianxin Catalyst Company also took important roles in the experiments. People (F. Wei) from the General Research Institute for Nonferrous Metals (Beijing, China) helped in the SEM.

Conflicts of Interest: The authors have no commercial interest for the reported results. 


\section{References}

1. LeValley, T.L.; Richard, A.R.; Fan, M. The progress in water gas shift and steam reforming hydrogen production technologies-A review. Int. J. Hydrog. Energy 2014, 39, 16983. [CrossRef]

2. Kumar, N.; Spivey, J.J. Direct Conversion of Syngas to Chemicals Using Heterogeneous Catalysts. In Encyclopedia of Sustainable Technologies; Abraham, M.A., Ed.; Elsevier: Amsterdam, The Netherlands, 2017; p. 605.

3. Bukur, D.B.; Todic, B.; Elbashir, N. Role of water-gas-shift reaction in Fischer-Tropsch synthesis on iron catalysts: A review. Catal. Today 2016, 275, 66. [CrossRef]

4. Zhu, M.; Wachs, I.E. ron-Based Catalysts for the High-Temperature Water-Gas Shift (HT-WGS) Reaction: A Review. ACS Catal. 2016, 6, 722. [CrossRef]

5. Meunier, F.C.; Tibiletti, D.; Goguet, A.; Shekhtman, S.; Hardacre, C.; Burch, R. On the complexity of the water-gas shift reaction mechanism over a $\mathrm{Pt} / \mathrm{CeO} 2$ catalyst: Effect of the temperature on the reactivity of formate surface species studied by operando DRIFT during isotopic transient at chemical steady-state. Catal. Today 2007, 126, 143. [CrossRef]

6. Carter, H.J.; Hutchings, J.G. Recent Advances in the Gold-Catalysed Low-Temperature Water-Gas Shift Reaction. Catalysts 2018, 8, 627. [CrossRef]

7. Yao, S.; Zhang, X.; Zhou, W.; Gao, R.; Xu, W.; Ye, Y.; Lin, L.; Wen, X.; Liu, P.; Chen, B.; et al. Atomic-layered Au clusters on $\alpha-\mathrm{MoC}$ as catalysts for the low-temperature water-gas shift reaction. Science 2017, $357,389$. [CrossRef] [PubMed]

8. Rodriguez, J.A. Gold-based catalysts for the water-gas shift reaction: Active sites and reaction mechanism. Catal. Today 2011, 160, 3. [CrossRef]

9. Idakiev, V.; Yuan, Z.Y.; Tabakova, T.; Su, B.L. Titanium oxide nanotubes as supports of nano-sized gold catalysts for low temperature water-gas shift reaction. Appl. Catal. A Gen. 2005, 281, 149. [CrossRef]

10. Fu, Q.; Deng, W.; Saltsburg, H.; Flytzani-Stephanopoulos, M. Activity and stability of low-content gold-cerium oxide catalysts for the water-gas shift reaction. Appl. Catal. B Environ. 2005, 56, 57. [CrossRef]

11. Nikolova, D.; Edreva-Kardjieva, R.; Gouliev, G.; Grozeva, T.; Tzvetkov, P. The state of (K)(Ni)Mo/ $\gamma-\mathrm{Al} 2 \mathrm{O} 3$ catalysts after water-gas shift reaction in the presence of sulfur in the feed: XPS and EPR study. Appl. Catal. A Gen. 2006, 297, 135. [CrossRef]

12. Newsome, D.S. The Water-Gas Shift Reaction. Catal. Rev. 1980, 21, 275. [CrossRef]

13. Liu, B.; Zong, Q.; Du, X.; Zhang, Z.; Xiao, T.; AlMegren, H. Novel sour water gas shift catalyst (SWGS) for lean steam to gas ratio applications. Fuel Process. Technol. 2015, 134, 65. [CrossRef]

14. Liu, B.; Zong, Q.; Edwards, P.P.; Zou, F.; Du, X.; Jiang, Z.; Xiao, T.; AlMegren, H. Effect of Titania Addition on the Performance of CoMo/Al2O3 Sour Water Gas Shift Catalysts under Lean Steam to Gas Ratio Conditions. Ind. Eng. Chem. Res. 2012, 51, 11674. [CrossRef]

15. Senanayake, S.D.; Evans, J.; Agnoli, S.; Barrio, L.; Chen, T.-L.; Hrbek, J.; Rodriguez, J.A. Water-Gas Shift and CO Methanation Reactions over Ni-CeO2(111) Catalysts. Top. Catal. 2011, 54, 34. [CrossRef]

16. $\mathrm{Xu}, \mathrm{J}$.; Froment, G.F. Methane steam reforming, methanation and water-gas shift: I. Intrinsic kinetics. AIChE J. 1989, 35, 88. [CrossRef]

17. Ma, L.; Sun, Y.; Wang, J. Application of Low Water-gas Ratio Shift Process in Shell Coal Gasification. Coal Chem. 2011, 39, 46.

18. Pal, D.; Chand, R.; Upadhyay, S.; Mishra, P. Performance of water gas shift reaction catalysts: A review. Renew. Sustain. Energy Rev. 2018, 93, 549. [CrossRef]

19. Copperthwaite, R.G.; Gottschalk, F.M.; Sangiorgio, T.; Hutchings, G.J. Cobalt chromium oxide: a novel sulphur tolerant water-gas shift catalyst. Appl. Catal. 1990, 63, L11. [CrossRef]

20. Hou, P.; Meeker, D.; Wise, H. Kinetic studies with a sulfur-tolerant water gas shift catalyst. J. Catal. 1983, 80, 280. [CrossRef]

21. Ratnasamy, C.; Wagner, J.P. Water gas shift catalysis. Catal. Rev. 2009, 51, 325. [CrossRef]

22. Kristiansen, A. Understanding Coal Gasification; IEA Coal Research London: London, UK, 1996; Volume 86.

23. Wang, Z.; Yang, J.; Li, Z.; Xiang, Y. Syngas composition study. Front. Energy Power Eng. China 2009, 3, 369. [CrossRef]

24. Minchener, A.J. Coal gasification for advanced power generation. Fuel 2005, 84, 2222. [CrossRef] 
25. Wilhelm, D.J.; Simbeck, D.R.; Karp, A.D.; Dickenson, R.L. Syngas production for gas-to-liquids applications: technologies, issues and outlook. Fuel Process. Technol. 2001, 71, 139. [CrossRef]

26. Fuertes, A.; Alvarez, D.; Rubiera, F.; Pis, J.; Marban, G.; Palacos, J. Surface area and pore size changes during sintering of calcium oxide particles. Chem. Eng. Commun. 1991, 109, 73. [CrossRef]

27. Dias, J.; Assaf, J. Influence of calcium content in $\mathrm{Ni} / \mathrm{CaO} / \gamma-\mathrm{Al} 2 \mathrm{O} 3$ catalysts for $\mathrm{CO} 2$-reforming of methane. Catal. Today 2003, 85, 59. [CrossRef]

28. Peng, Y.; Meng, Z.; Zhong, C.; Lu, J.; Yu, W.; Yang, Z.; Qian, Y. Hydrothermal Synthesis of MoS2 and Its Pressure-Related Crystallization. J. Solid State Chem. 2001, 159, 170. [CrossRef]

29. Ferrari, A.C.; Robertson, J. Interpretation of Raman spectra of disordered and amorphous carbon. Phys. Rev. B 2000, 61, 14095. [CrossRef]

30. Guisnet, M.; Ribeiro, F.R. Deactivation and Regeneration of Zeolite Catalysts; World Scientific: Singapore, 2011; Volume 9.

31. Mauge, F.; Lamotte, J.; Nesterenko, N.S.; Manoilova, O.; Tsyganenko, A.A. FT-IR study of surface properties of unsupported MoS2. Catal. Today 2001, 70, 271. [CrossRef]

32. Van Haandel, L.; Hensen, E.; Weber, T. FT-IR study of NO adsorption on MoS2/A12O3 hydrodesulfurization catalysts: Effect of catalyst preparation. Catal. Today 2017, 292, 67. [CrossRef]

33. Hagen, J. Industrial Catalysis: A Practical Approach; John Wiley \& Sons: Hoboken, NJ, USA, 2015.

34. Leach, B. Applied Industrial Catalysis; Elsevier: Amsterdam, The Netherlands, 2012.

(C) 2019 by the authors. Licensee MDPI, Basel, Switzerland. This article is an open access article distributed under the terms and conditions of the Creative Commons Attribution (CC BY) license (http://creativecommons.org/licenses/by/4.0/). 